\title{
Robust estimates of climate-induced hydrological change in a temperate mountainous region
}

\author{
N. Köplin • O. Rößler • B. Schädler • R. Weingartner
}

Received: 4 April 2013 / Accepted: 19 November 2013 / Published online: 8 December 2013

(C) Springer Science+Business Media Dordrecht 2013

\begin{abstract}
A sustainable water resources management depends on sound information about the impacts of climate change. This information is, however, not easily derived because natural runoff variability interferes with the climate change signal. This study presents a procedure that leads to robust estimates of magnitude and Time Of Emergence (TOE) of climate-induced hydrological change that also account for the natural variability contained in the time series. Firstly, natural variability of 189 mesoscale catchments in Switzerland is sampled for 10 ENSEMBLES scenarios for the control (1984-2005) and two scenario periods (near future: 2025-2046, far future: 2074-2095) applying a bootstrap procedure. Then, the sampling distributions of mean monthly runoff are tested for significant differences with the Wilcoxon-Mann-Whitney test and for effect size with Cliff's delta $d$. Finally, the TOE of a climate change induced hydrological change is determined when at least eight out of the ten hydrological projections significantly differ from natural variability. The results show that the TOE occurs in the near future period except for high-elevated catchments in late summer. The significant hydrological projections in the near future correspond, however, to only minor runoff changes. In the far future, hydrological change is statistically significant and runoff changes are substantial. Temperature change is the most important factor determining hydrological change in this mountainous region. Therefore, hydrological change depends strongly on a catchment's mean elevation. Considering that the hydrological changes are predicted to be robust in the near future highlights the importance of accounting for these changes in water resources planning.
\end{abstract}

Electronic supplementary material The online version of this article (doi:10.1007/s10584-013-1015-x) contains supplementary material, which is available to authorized users.

N. Köplin · O. Rößler • B. Schädler · R. Weingartner Oeschger Centre for Climate Change Research, University of Bern, Zähringerstrasse 25, 3012 Bern, Switzerland

N. Köplin $(\varangle) \cdot$ O. Rößler $\cdot$ B. Schädler $\cdot$ R. Weingartner Institute of Geography, Hydrology Group, University of Bern, Hallerstrasse 12, 3012 Bern, Switzerland e-mail: nina.koeplin@web.de 


\section{Introduction}

Robust estimates of climate-induced hydrological changes are of vital importance for society due to the dependence on water resources for energy production, as drinking water supply or for irrigation, for example. This importance is reflected in the persistently increasing number of climate change impact studies in hydrology. The IPCC defines climate change as a change in the state of the climate that is typically identified by changes in the mean of a variable of interest (Hegerl et al. 2007). There is, however, also natural variability on all time scales and in every process related to climate (Hegerl et al. 2007) that needs to be considered when analyzing climate induced changes of these processes.

Only recently, this need was recognized in the hydrological climate impact community and state-of-the-art impact studies systematically incorporate natural climate and runoff variability in their analyses. Hänggi (2011) and Liu et al. (2013), for example, applied resampling procedures to assess the natural variability of runoff in the control period. Ledbetter et al. (2012) also use a resampling method but they sample natural variability of precipitation in the control and in the scenario period and use these resampled time series as model input. Arnell (2011) incorporates natural climate variability of the control period by examining seven 30 years periods from a long unforced climate model run. The study by Fatichi et al. (2013), finally, applies a weather generator to compile several time series for the control and three different climate scenarios driven by the same global circulation model (GCM).

Despite the fact that the above-mentioned studies either sample natural variability in the control period alone or in both the control and the scenario period, all studies have in common that they compare the spread due to natural variability with the spread of the climate change signals, i.e. their evaluation is a posteriori. The approach suggested here differs from the mentioned studies in that those projected changes that are not robust, i.e. that are within the natural variability, are a priori excluded from the further analysis.

The present study aims at detecting those hydrological climate change signals that are outside of natural runoff variability. This is done for a comprehensive set of 189 mesoscale catchments that represent the variety of different catchment types in a temperate mountainous region. Natural variability is estimated by resampling of the control and the scenario time series. If the sample distributions differ statistically significant and the effect size is large, then a projection is defined to be outside of natural variability. The combination of resampling with a statistical test and an effect size measure thereby leads to a very robust estimation of hydrological change, and this procedure is novel to hydrological climate impact studies. Once the significant hydrological signals are identified, they are analysed in more detail and the changes in runoff generating processes are verified by the example of four case study catchments. Besides these main analyses, the results are compared to the results of Köplin et al. (2012), who studied the same set of catchments but did not account for natural runoff variability.

To summarize, this paper studies "when", "where" and "why" the runoff in Switzerland significantly changes. The first two questions "when" and "where" focus on the detection in the sense of Merz et al. (2012), i.e. the provision of evidence that an observed change is beyond the natural variability. In other studies and also for the remainder of this study, the "when" is referred to as Time Of Emergence (TOE; Giorgi and Bi 2009; Hawkins and Sutton 2012). The 'why' concerns the question whether the change is more related to temperature, precipitation or both variables in combination, and in this respect it is a question of attribution. 


\section{Data and methods}

\subsection{Climate and runoff projections}

This paper on hydrological climate-impact in Switzerland is one in a series that are all based on the same dataset of hydrological projections, and that were compiled within the national Swiss research project Climate Change and Hydrology in Switzerland (CCHydro; FOEN 2012). The dataset is described in detail in the preceding publications (Köplin et al. 2012; 2013) and here only a very brief description of the key information is provided. For 189 catchments distributed over Switzerland the parameters of the semi-distributed and conceptual but physicallybased hydrological model PREVAH (Gurtz et al. 1999; Viviroli et al. 2009a; Zappa and Gurtz 2003) were calibrated and regionalized applying a procedure described in Viviroli et al. (2009b; 2009c). The selection of catchments represents the variety of runoff regime types and climates in this mountainous environment.

Ten GCM-RCMs from the ENSEMBLES project (van der Linden and Mitchell 2009) were applied to generate hydrological projections. The climate scenario data were statistically postprocessed using an extended delta change approach (Bosshard et al. 2011) and were provided through the $\mathrm{CH} 2011$ initiative (CH2011 2011). This delta change approach differs from common delta change methods (that use e.g. only monthly means) in that it estimates the mean annual cycles for temperature $(\mathrm{T})$ and precipitation $(\mathrm{P})$ by spectral smoothing which reduces the noise in the signal that is caused by natural variability. The annual cycles of climate change signals for $\mathrm{T}$ and $\mathrm{P}$ are available at daily resolution for every climate station in the study domain (188 temperature and 565 precipitation stations within an area of $41,285 \mathrm{~km}^{2}$ ). The T deltas are added to the observed time series, and the observations are multiplied by the $\mathrm{P}$ signals to generate $\mathrm{T}$ and $\mathrm{P}$ scenario time series to run the hydrological model with. The scenarios are based on the A1B emission scenario (IPCC 2000) and are provided for two scenario periods relative to the control period from 1984 to 2005: the near future from 2025 to 2046 and the far future from 2074 to 2095 . Those two periods represent the furthest planning horizon for water management on the one hand (near future) and a significant climate change with potentially severe impact on the other (far future).

To account for glacier retreat, glacier scenarios were applied that were compiled within the CCHydro project (Linsbauer et al. 2013) and that are based on the same set of climate scenarios. The glacier retreat model of Linsbauer et al. (2013) assumes a rise of the glaciers' equilibrium line altitude of $150 \mathrm{~m}$ per $1 \mathrm{~K}$ temperature increase and a subsequent adaptation of the glacier area that occurs delayed with a mean response time of 50 years. The glacier scenarios are static for each scenario period, though, i.e. there is only one state of glacier area that is representative of the temperature increase for the respective period, which is a simplification.

Based upon this setting, continuous hydrological projections in hourly resolution for 189 mesoscale catchments were produced. The continuous hydrological projections were then aggregated to monthly resolution to be in line with the data set in Köplin et al. (2012).

\subsection{Climate changes in the study domain}

As a basis for the interpretation of the results in this study it is indispensable to understand how precipitation and temperature change. Therefore, a brief summary of the main changes in climate is provided in the following. The projected precipitation change in the near future period is mostly within the bounds of the estimated control period's natural variability (Bosshard et al. 2011). The only clear precipitation change signals can be found in the far 
future: a strong decrease in summer and a less pronounced increase in winter precipitation, which most climate scenarios in the ensemble indicate (CH2011 2011). The projected increase in winter precipitation is most distinct in the northern and northwestern part of Switzerland which is in general the lower region (catchments' mean elevation $<1,500 \mathrm{~m}$ a.s.1.). Regarding projected temperature increase, there is a clear signal of increasing temperature throughout the year for both scenario periods which is most pronounced in summer and in higher elevations. In general, the temperature increase is much stronger in the far future period (CH2011 2011), and it appears over a larger elevational range, i.e. up to higher elevations than in the near future.

The uncertainty expressed as the spread of the climate projections is low for temperature, particularly in the near future. In the far future, the spread is somewhat larger, most obviously in summer, due to the overall larger change values. All projected temperature values are, however, far above both, the control period values and their natural variability. Therefore, the temperature signal is very clear. The uncertainty of projected precipitation changes is larger, as stated above, especially in the near future period. In the southern part of Switzerland, only half of the projections agree in the sign of the change, for example. The increase in the far future's winter precipitation is more unclear in the high alpine areas, and the uncertainty in decreasing summer precipitation in the far future is generally small: nearly all climate scenarios project a clear decrease in summer precipitation for that period. These spatio-temporally varying uncertainties are summarized in the CH2011 report (CH2011 2011: 82), which show both the climate change signals and their spread or uncertainty on a seasonal basis.

\subsection{Analysis of runoff changes}

\subsubsection{Bootstrap procedure}

We applied a bootstrap procedure (Efron 1979) to account for the natural variability in our runoff time series, both in that of the control as well as the scenario periods. Bootstrapping was already applied in other hydrological impact studies to resample natural variability, e.g. in Hänggi (2011), Ledbetter et al. (2012) and Liu et al. (2013). It is based on the assumption that the data to analyze, in this case the 22 years time series of monthly runoff for the control and the scenario periods, are a random realization of a larger population defined through the values in the sample. One generates an arbitrary number of time series of length $n$ (here: $n=22$ ) out of the original data by resampling with replacement, i.e. a value that is resampled is "replaced" or in other words put back into the original data pool. Thereby, some values can occur several times in the resampled time series, other not at all. For each of those bootstrap samples the statistic of interest is computed (here: mean monthly runoff). We drew 1,000 bootstrap samples for each month in the time series, separately, i.e. we applied a block-resampling and generated a bootstrap sample distribution for every month. We assumed that the spread of the bootstrapped mean monthly runoff represents natural variability in the data and the change signal is the difference between control and scenario.

\subsubsection{Statistical significance and effect size}

We then tested the two distributions for statistically significant differences, where the null hypothesis assumes that the two distributions are identical. We applied the non-parametric Wilcoxon-Mann-Whitney test (Mann and Whitney 1947; Wilcoxon 1945) to test whether the null hypothesis should be rejected on a $5 \%$ significance level or not. However, through the rather large sample sizes of 1,000 bootstrapped mean monthly values, the test might indicate a statistical significance that has no physical significance or meaning (von Storch and Zwiers 
2001). Therefore, we additionally computed Cliff's delta $d$ (Cliff 1993) as an effect size measure that evaluates the strength of the signal. Cliff's delta ranges from -1 to 1 . The delta is negative (i.e. it ranges from 0 to -1 ) if the projected runoff change is a decrease, and it is positive (between 0 and 1 ) if an increase is projected. A value of $0.5(-0.5)$ means that there is a $75 \%$ chance that a randomly drawn value from the scenario distribution is greater (smaller) than a value from the control period sample distribution. A value of 0 (no effect) accordingly means that there is a $50 \%$ chance that a scenario distribution value is greater/smaller than a control value. We defined a threshold value for $d$ of $0.5(-0.5)$ above which (below which) a statistically significant signal is assumed to be physically significant, too. So, the determination of statistically significant hydrological projections is based on a two-stage evaluation-process: The Wilcoxon-Mann-Whitney test has to indicate a significant runoff change, and Cliff's delta $d$ should be either $>0.5$ or $<-0.5$ so that a given projection is assumed to be what we call a significant hydrological projection, i.e. a projection that is out of natural runoff variability. This is to prevent falsely accepting statistical significance as being also physically significant. Please see the supplementary material (Fig. S1) for a visualization of the procedure.

\subsubsection{Determining the time of emergence}

We conducted this analysis on a monthly basis for every hydrological projection, separately, i.e. for every climate scenario and period. The number of significant scenarios are summed per period, so that a value between 0 and 10 results for the near and the far future period, respectively. With this value we determine the Time Of Emergence (TOE) of hydrological change in the study domain. The TOE occurs in either one of the scenario periods if a high number, i.e. 8, 9 or 10 out of the 10 hydrological projections are significant as defined above, or in other words, if for a given catchment, month and period, $x$ out of 10 projections are outside of the natural runoff variability. We thereby follow the suggestions of von Storch and Zwiers (2013), who encourage expressing climate change impacts based on ensembles of climate scenarios in a more descriptive manner. It should be clearly stated, however, that we can only account for the natural variability that is contained in the control period series, because we apply climate scenarios that are post-processed with the delta change method. This statistical post-processing method assumes stationary frequency and intensity of precipitation, for example. Changes in frequency and intensity could, however, induce an additional change in the variability of monthly runoff.

\subsubsection{Further qualifying analysis}

To comprehensively assess the significance of hydrological change, one has to also consider the degree of change for a given catchment. Although the effect size quantifies the absolute change signals already, this can still correspond to minor relative changes in catchments with rather high runoff volumes. Therefore, we included an additional evaluation step, or a qualification of the significant hydrological projections. We computed change coefficients for every catchment and month, i.e. we divided the absolute monthly runoff-change by the mean annual runoff of a catchment. Thereby, the monthly change is weighted and one can assess whether this is a substantial change for a given catchment. This prevents us from misinterpreting large absolute changes that correspond to small relative changes or vice versa. Additionally, we assessed changes in the variation of monthly runoff by computing the coefficient of variation (CV) per month for the control and the scenario periods. The change from control to scenario is given as the ratio of scenario over control (Delta CV). Please note that the change coefficients and $\mathrm{CV}$ deltas are based on the ensemble mean of the ten 
hydrological projections per period. This means that these values do not reflect the variation among the climate scenarios, but act as an indicator to qualify large numbers of significant hydrological projections.

\section{Results and discussion}

\subsection{Time of emergence}

First, the spatially and annually distributed Time Of Emergence (TOE) should be discussed for the two scenario periods. We plotted the numbers of significant hydrological projections for all catchments on maps of Switzerland separately for every month to derive spatial and temporal patterns of the TOE. The monthly maps of TOE (single panels in Fig. 1) can be interpreted as follows: if grey is dominating a certain region, then the TOE is in the near future for that region and month, while a dominating black color indicates that the TOE is in the far future. With this figure, it is not intended to present the exact number of significant scenarios for each catchment, but to identify broader spatial patterns within the study area. With few exceptions, the TOE for the winter month is in the near future already. For spring there is no clear distinction between near and far future period: in early spring black tends to dominate the map while in late spring it is grey. In summer the higher elevated regions, which are roughly speaking catchments in the southern half of Switzerland, tend to have the TOE in the near future period while the catchments at lower elevations show significant signals only in the far future period, which is particularly obvious in August. This reflects results from Köplin et al. (2012). For autumn there is again no clear distinction between near and far future period and more over only few catchments show significant signals at all.

Considering that it is only the temperature which clearly changes in the near future (confer section 2.2), the significant runoff changes in the near future have to be ascribed to temperature effects alone. In this temperate mountainous region these temperature effects on runoff are, for example, enhanced liquid precipitation in winter and earlier snow and ice melt. The highly significant changes in the near future are for most months and catchments amplified in the far future, though, as is the temperature change.

What one cannot derive from the projections are, of course, conclusions about the time before and between the scenario periods. Taking into account the results from Hawkins and Sutton (2012), there might be a more differentiated pattern for the TOE if the projections were transient. They furthermore found large differences between climate scenarios, especially if different emission scenarios are considered. It is, therefore, important to emphasize that the validity of these results is restricted to the set of climate scenarios applied and their resulting hydrological projections. That is, in this case the changes in the mean state between control and scenario period are analyzed. This also applies to the glacier scenarios, for example, which are static during a time-slice and represent the mean temperature increase in the scenarios (cf. 2.1).

\subsection{Change coefficients}

In the analysis above, the TOE was found to occur in the near future for the majority of catchments and months. Here, the magnitude of hydrological change is additionally analyzed through change coefficients. The left side of Fig. 2 shows the results for the near future, colorcoded according to the associated change coefficients. As with Fig. 1 this depiction is meant to illustrate the spatial and temporal patterns, rather than to display the exact number of 

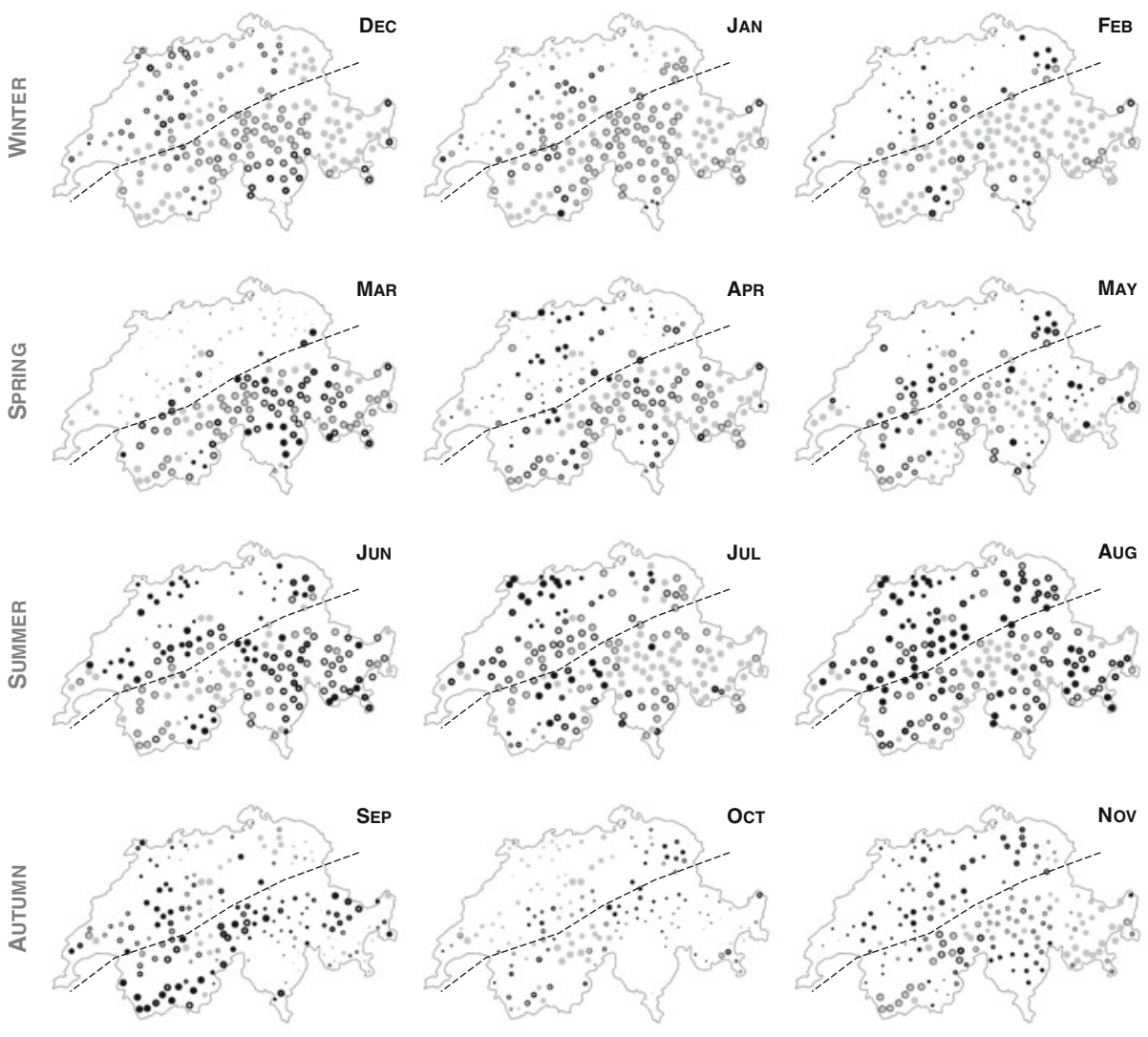

\section{LEGEND}

$\cdot 5 \cdot 6 \quad \cdot 7 \quad \cdot 8 \cdot 9 \quad \bullet 10$ out of 10 GCM-RCMs significant $\bullet$ near future period $\bullet$ far future period

Fig. 1 Number of significant hydrological projections for every catchment and month and both scenario periods (near future grey, far future black). The size of the points depicts the number of significant scenarios, only numbers of 5 or greater are displayed. Please note that the near future points are plotted on top of the far future ones, which means that wherever the number of significant scenarios in the near future is bigger, the black far future point is not visible. The location of a point is the centroid of a catchment. The dashed lines indicate the 1,500 $\mathrm{m}$ a.s.1. isohypse dividing Switzerland in a northern lower elevated part and a southern higher elevated part

significant projections per catchment. The associated change coefficients in the near future period are mostly small or not visible (i.e. in the range of $-0.1-0.1$ ) which clearly puts the previous result into perspective. Only alpine catchments in the near future's summer are highly significant and the associated change coefficients are large, too. The strong decrease in July runoff in the near future is the result of temperature rather than precipitation change, as mentioned above, because earlier and less snow and ice melt induce noticeable deficits in those catchments in summer, whereas precipitation changes merely (confer 2.2). In the far future, the decreasing summer precipitation and even higher temperatures in the scenarios intensify the decreasing summer runoff in alpine catchments. Less summer precipitation also causes the summer runoff to decrease in catchments at lower elevations that are not characterized through pronounced melt runoff in spring or summer. In the far future's winter there is a clear signal of runoff increase, which is most pronounced for the higher elevated catchments. 
Near future period (2025-2046)

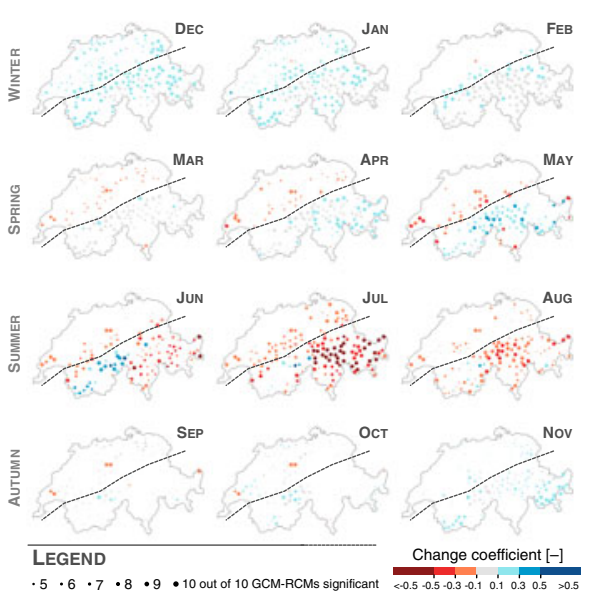

Far future period (2074-2095)

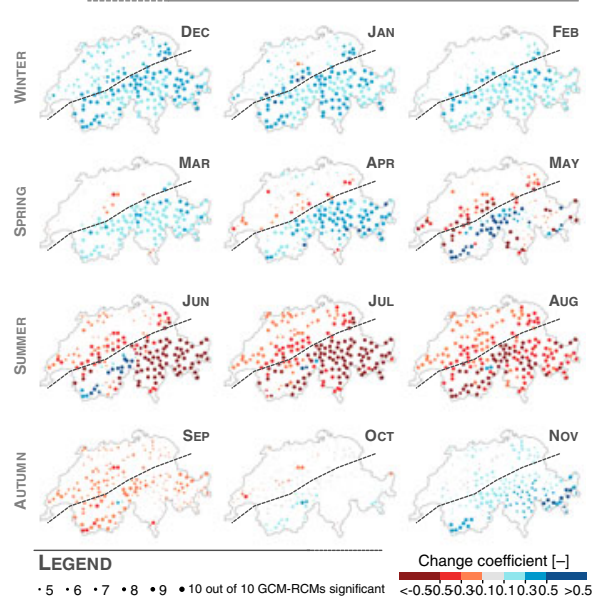

Fig. 2 The near and far future periods are displayed left and right respectively. The size of the points depicts the number of significant signals per catchment as shown in Fig. 1. The color shows the catchments' monthly change coefficient (ensemble mean); red colors depict decreasing, blue colors increasing runoff. For change coefficients between -0.1 and 0.1 no clear change signal can be observed. The dashed lines indicate the 1,500 $\mathrm{m}$ a.s.1. isohypse dividing Switzerland in a northern lower elevated part and a southern higher elevated part

This is surprising, though, because the precipitation increase for the same season and period is more distinct in the lower regions (see Section 2.2). The reason for this mismatch is once again the temperature effect which dominates the change in runoff in that it shifts the type of precipitation from solid to liquid. Or put another way, those catchments receive a stronger increase in liquid precipitation, which will be substantiated at the end of the results section with the example of the four case studies.

\subsection{Elevation dependency}

Seemingly, there is a strong relationship between the runoff changes that are related to temperature and a catchment's mean elevation, which confirms previous studies (Birsan et al. 2005; Horton et al. 2006; Köplin et al. 2012). This effect of the catchments mean elevation should be studied in more detail in the following. Figure 3 reveals that there is no obvious relationship between the size of the points and the elevation, which means that a significant change does not depend on a catchment's mean elevation. But there is again an obvious relationship between the catchments' mean elevations and their change coefficients, which was found before in Fig. 2 but which is more obvious in this depiction. In winter (toprow in Fig. 3), the projected runoff generally increases but most pronounced within a defined range of mean catchment elevations between 1,000 and 2,500 $\mathrm{m}$ a.s.1. This range gets narrower towards the end of the season (1,200-2,000 $\mathrm{m}$ a.s.1.). In spring the sample of study catchments is divided into catchments at lower elevation (below 1,500 $\mathrm{m}$ a.s.1.) where runoff is projected to decrease and those at higher elevations where it increases. With each month the projected decrease stretches to higher elevations. In summer, almost all catchments show decreasing runoff with the exception of some very high elevated catchments, which still profit from glacier melt. The overall pattern can be described as follows: the higher the catchment, the stronger the runoff-decrease. This depicts the interaction of precipitation decrease and melt deficit which results in these strong changes. However, there seems to be an upper limit of this 


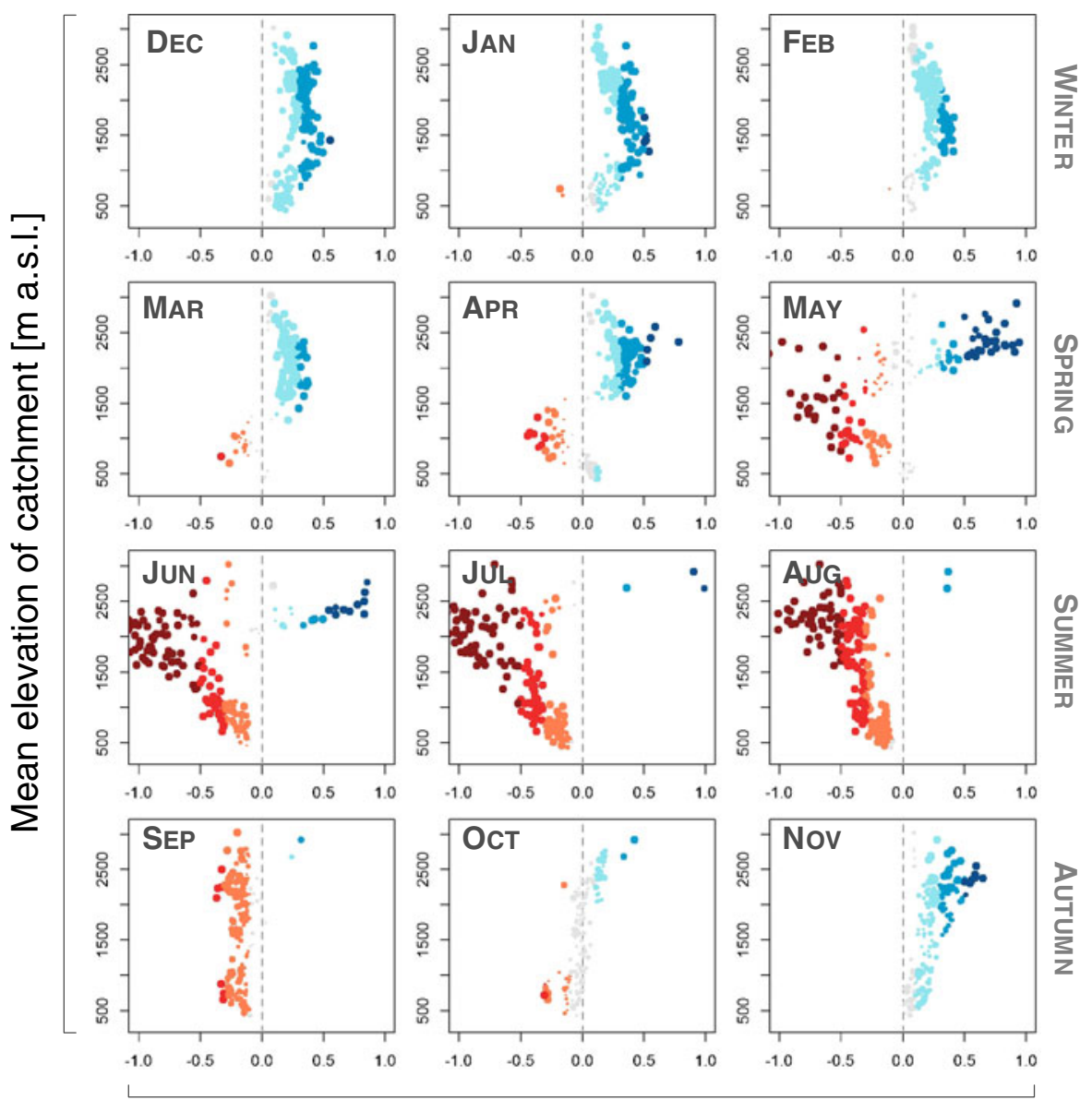

Change coefficient $[-]$

\section{LEGEND}

\section{$\cdot 5 \cdot 6 \cdot 7 \cdot 8 \cdot 9 \cdot 10$ out of $10 \mathrm{GCM}-\mathrm{RCMs}$ significant}

Fig. 3 Change coefficient ( $x$-axis) and number of significant scenarios (symbol size) as a function of the catchments' mean elevation ( $y$-axis). Each point represents one catchment and each panel shows 1 month. Only the results for the far future period are shown. To ease comparison with Fig. 2, the points are color-coded with respect to their change coefficients although this contains the same information as their position on the $x$-axis

relationship, again at 2,500 $\mathrm{m}$ a.s.l. In autumn, no consistent pattern is detectable; it is as the spring a transitional season: at the beginning it is still influenced from the summer and at the end the winter pattern is already perceptible.

\subsection{Coefficient of variation}

All presented analyses so far focused on changes in the mean, but climate-change impacts also entail changes in other statistics that describe the variation of the data, for example. The coefficient of variation (CV) was computed as a dimensionless measure of variation in 
monthly runoff. Its change (Delta CV) is displayed spatially distributed as it was done for the change coefficient in Fig. 2. Please refer to the supplementary material for the visualization (Fig. S2). When comparing Fig. S2 and the right half of Fig. 2 (the far future period), it is obvious that increasing runoff corresponds to an increasing coefficient of variation (values greater one; pink and purple colors in Fig. S2). The strongly decreasing change coefficients in summer, however, are not associated with a decreasing coefficient of variation; there is no clear pattern for the summer Delta CV at all. The first observation can be easily explained: the increasing runoff most of all results from the increased proportion of liquid precipitation as set out earlier. More liquid precipitation is equivalent to more variability, i.e. higher CVs. To explain the second observation (strongly decreasing runoff with no associated change in $\mathrm{CV}$ ), one needs to consider that summer runoff in the alpine catchments is characterized through both, convective rainfall and melt from snow and ice. There will still be convective rainfall events (the applied climate scenarios do not consider changes in the extremes) and the formerly steady supply of melt to summer runoff is reduced. Depending on the proportion of this melt, the runoff variation in summer might actually increase, which can be observed for a number of catchments. It should be mentioned again, however, that these changes in CV reflect only mean climate changes due to the applied delta change scenarios and do not include changes in the variability of the climate variables itself. Considering that, the clear increase in winter is remarkable.

\subsection{Case study analysis}

With the example of four case studies the presented results are summarized and substantiated in the following. The case studies cover the range of Swiss catchments' mean elevations and are, therefore, representative of the study region (Köplin et al. 2012). The changes in runoff, precipitation and melt (Fig. 4) are displayed for each of the four case study catchments starting with the lowest elevated catchment Birs (upper left part of Fig. 4) and moving clockwise to the highest elevated catchment Borgne (lower left part of Fig. 4). Three above-mentioned key findings are examined on the basis of these case studies: (1) in the near future, temperature change dominates hydrological change, (2) the importance of melt processes gradually increases with mean catchment elevation and (3) in the far future, temperature- and precipitation-changes interact and mutually amplify their impact on runoff.

To review the first key finding that concerns only the near future, the focus is on the left column of subpanels for each catchment in Fig. 4. One can see that total winter precipitation (bold blue curves) only marginally increases (please note the differing scales of the Birs catchment, upper-left). More important is the increase in liquid precipitation in the two lower elevated catchments (upper half of Fig. 4) that directly generates runoff. In the Birs catchment this increase partly compensates for declining snow melt contribution to winter runoff, while in the Kleine Emme increased liquid precipitation results more or less directly in enhanced winter runoff. This kind of temperature effect is not present in the high elevated catchments because the near future temperature increase is not strong enough to alter the temperature regime in those regions. There, the temperature change affects melt in spring and in summer. In the highest catchment Borgne, the snow melt season is shifted resulting in a relative surplus in spring and a subsequent deficit during summer. This means, the amount of snow melt in this catchment is approximately the same in the near future, but it occurs earlier and thereby alters the runoff regime. Because the catchment receives more liquid precipitation in late spring in addition (Fig. 4, lower left), the runoff increase is even stronger than the subsequent decrease. In the Vorderrhein catchment the temperature effect on runoff in summer is restricted to declining melt contribution, resulting from the deficit in solid precipitation in winter and spring 

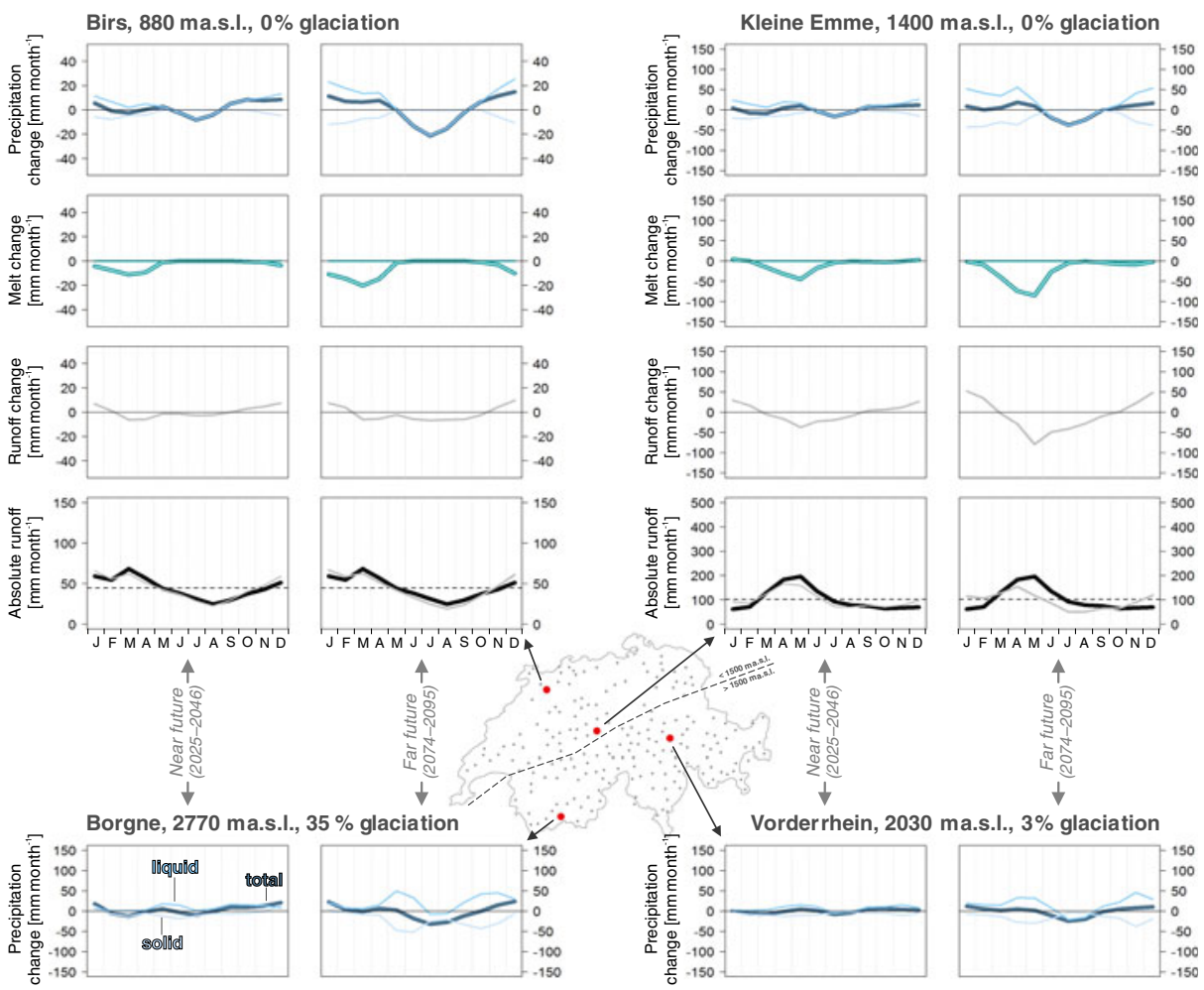

Vorder rhein, 2030 ma.s.I., 3\% glaciation
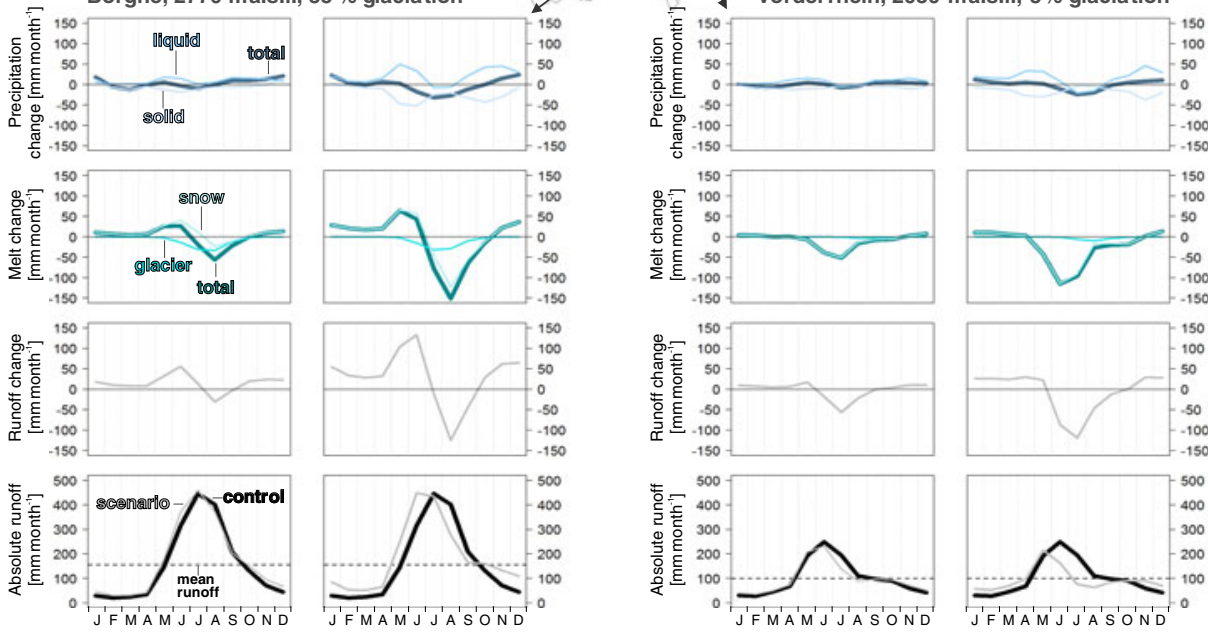

Fig. 4 Absolute changes of precipitation, melt and runoff and absolute monthly runoff for four case studies. Please note that the ensemble mean of the hydrological projections is shown per scenario period. The two case studies in the upper half of the figure (Birs and Kleine Emme) represent catchments at lower elevations $(<1,500 \mathrm{~m}$ a.s.1., see overview in the middle); the two catchments in the lower half of the figure (Borgne and Vorderrhein) are representative of catchments with higher mean elevations. For each catchment the projected changes for the near future are shown in the left column of subpanels, the far future is depicted in the respective right column. The curves are explained in the near future column of the Borgne catchment, lower-left. Please note the differing scales for the Birs catchment, upper left part of the figure

and the thus smaller snowpack. This effect is also visible for the Kleine Emme except that the melt deficit occurs already in spring. So, the first key finding is proved by the case studies: the near future runoff change is mostly determined through temperature effects. 
The second key finding that melt-processes gain in importance for hydrological change with increasing mean elevation of a catchment is trivial given the demonstrated importance of temperature in this environment. Nevertheless, the detailed analysis of case studies depicts this very nicely. With increasing catchment mean elevation, the absolute amount of melt deficit gradually increases, too. Depending on the catchment's mean elevation, the resulting runoff change (bottom-row in each sub-plot) varies from a shift of the annual peak for the highest catchment (Borgne) over a clear decrease in summer runoff (Vorderrhein) to a decrease in summer that is compensated by an increase in winter (Kleine Emme) and finally to only marginal changes in runoff for the lowest elevated catchment (Birs).

The third key finding finally focuses on the far future period, so it is the respective right column of subpanels to examine in the following. In winter of the far future, total precipitation increases slightly but there is a marked increase in liquid precipitation. These two changes cause clearly increasing winter runoff in catchments at all elevations. For the two high elevated catchments in the sample this increase continues in spring and is even amplified by earlier melt in the Borgne catchment as set out above. Total precipitation decreases in all catchments in the far future's summer. In the Borgne, however, there is no change in liquid precipitation in that season (i.e. total precipitation decreases, but liquid precipitation increases), which is why the decrease in total precipitation has no influence on runoff in this catchment. In the two medium elevated catchment, which are within the elevational range of "climate change sensitive catchments" as defined by Köplin et al. (2012; range: 1000-2500 m a.s.1.), decreasing melt and decreasing total precipitation cause a more (Kleine Emme) or less (Vorderrhein) prolonged period of substantially decreasing summer runoff. To summarize, higher temperatures in the scenario result in higher proportions of liquid precipitation in the far future's winter, which together with increasing total precipitation causes winter runoff to increase over the whole elevational gradient. This confirms the key findings derived from Fig. 3. Regarding decreasing summer runoff, less total precipitation and less melt runoff coincide and lead to a lowering of the annual peak in summer. This is, however, only apparent where melt runoff was relevant for summer runoff in the control period, i.e. in catchments with a mean elevation above approximately 1,000 $\mathrm{m}$ a.s.l. and below an upper limit of 2,500 $\mathrm{m}$ a.s.l. A catchment's mean elevation determines the characteristic of the runoff change, i.e. whether it's rather an extended but more moderate decrease over the whole summer half-year (melt deficit in spring is followed by precipitation deficit in summer, Kleine Emme) or a more accentuated and strong decrease restricted to the summer months only (melt and precipitation deficit coincide, Vorderrhein). This is due to the precipitation decrease that is stationary in time for all catchments and the timing of the melt deficit that depends on catchment elevation. Above the upper limit of 2,500 $\mathrm{m}$ a.s.1., a different interplay of melt and precipitation change is dominant: there, melt runoff (also from remaining glaciers) is still present in the far future but it occurs already in spring and is accompanied by more liquid precipitation in that season, which results in a shift of the annual peak rather than a general lowering of the runoff.

\section{Conclusions}

This paper presented a method that allows robust estimates of climate-induced hydrological change which at the same time account for the natural variability associated with hydrological time series. Without accounting for the inherent natural variability, one might overestimate the magnitude or the Time Of Emergence (TOE) of the hydrological change signal and arrive at a wrong decision when, for example, water resources planning is envisaged.

In this study, the TOE was found to be already in the near future for the majority of catchments and months. This is somewhat surprising considering that the near future 
hydrological change was found to be of minor importance in Köplin et al. (2012). The TOE results were qualified, though, when additionally considering the change coefficients. In conclusion this means, although the hydrological change is comparatively small in the near future, these small changes are already outside of the natural variability as defined in this study. They are, therefore, an indicator that the hydrological systems in Switzerland are fundamentally changing under 21 st century's climate change.

A significant runoff increase in winter is mainly projected for the higher elevated catchments, which disagrees with the spatial pattern of winter precipitation increase that is most clear in lower elevated regions. This discrepancy could be explained by the dominant temperature effect which is stronger than the precipitation change. The strong dependency of hydrological change on temperature change can also be interpreted as strong elevation dependency of the hydrological change signal, a pattern that has been repeatedly found (e.g. Fatichi et al. 2013; Horton et al. 2006). The significance of the hydrological projections, however, does not show such an elevation dependency or in other words, significant changes occur over the whole elevational gradient and therefore all over Switzerland. The elevation dependency is thus related to the magnitude of the signal only.

Regarding the comparison with the results presented in Köplin et al. (2012), who did not account for natural runoff variability, it can be stated that the projected runoff changes are generally confirmed through the analysis here, which at the same time means that the changes in the study region are robust changes. It is very likely that this clear picture emerges due to the fact that temperature and its change is important for hydrological change rather than the less clear precipitation change signal. This means that the projected signal of hydrological change is likely to be robust, even if changes in precipitation frequency would be accounted for in the applied climate scenarios. This applies, however, only to changes in the mean annual cycle of runoff, i.e. the runoff regimes that were studied here. Changes in droughts and floods are subject to other processes and have to be assessed separately. The fact that already the mean changes are robust and mostly large, however, is reason enough to carefully review and adjust national water management strategies.

Acknowledgments This study was funded by the Swiss Federal Office for the Environment (FOEN). The authors would like to thank the FOEN, the Swiss Federal Statistical Office (SFSO) and the Federal Office for Meteorology and Climatology (MeteoSwiss) for providing the necessary input data. The delta change scenario data were distributed by the Center for Climate Systems Modeling (C2SM). The data were derived from regional climate simulations of the EU FP6 Integrated Project ENSEMBLES (Contract number 505539) whose support is gratefully acknowledged. The dataset has been prepared by Thomas Bosshard at ETH Zurich, partly funded by swisselectric/Swiss Federal Office of Energy (SFOE) and CCHydro/Swiss Federal Office for the Environment (FOEN). The authors would like to thank Frank Paul and Andreas Linsbauer, Institute of Geography, University of Zurich (GIUZ), for providing the scenarios of glacier retreat.

\section{References}

Arnell NW (2011) Uncertainty in the relationship between climate forcing and hydrological response in UK catchments. Hydrol Earth Syst Sci 15(3):897-912

Birsan M, Molnar P, Burlando P, Pfaundler M (2005) Streamflow trends in Switzerland. J Hydrol 314(1-4):312329

Bosshard T, Kotlarski S, Ewen T, Schär C (2011) Spectral representation of the annual cycle in the climate change signal. Hydrol Earth Syst Sci 15(9):2777-2788

CH2011 (2011) Swiss Climate Change Scenarios CH2011. C2SM, MeteoSwiss, ETH, NCCR Climate, and OcCC, Zürich, Switzerland. http://data.c2sm.ethz.ch/dataset/ch2011/report/CH2011report.pdf. Accessed 15 September 2013 
Cliff N (1993) Dominance statistics: ordinal analysis to answer ordinal questions. Psychol Bull 114:494-509

Efron B (1979) Bootstrap methods: another look at the jackknife. Ann Stat 7(1):1-26

Fatichi S, Rimkus S, Burlando P, Bordoy R, Molnar P (2013) Elevational dependence of climate change impacts on water resources in an Alpine catchment. Hydrol Earth Syst Sci Discuss 10(3):3743-3794

FOEN (2012) Effects of Climate Change on Water Resources and Waters. Synthesis report on "Climate Change and Hydrology in Switzerland" (CCHydro) project. Federal Office for the Environment, Bern. UmweltWissen No 1217. http://www.bafu.admin.ch/publikationen/publikation/01670/index.html?lang=en. Accessed 15 September 2013

Giorgi F, Bi X (2009) Time of emergence (TOE) of GHG-forced precipitation change hot-spots. Geophys Res Lett 36(6), L06709

Gurtz J, Baltensweiler A, Lang H (1999) Spatially distributed hydrotope-based modelling of evapotranspiration and runoff in mountainous basins. Hydrol Process 13:2751-2768

Hänggi P (2011) Auswirkungen der hydroklimatischen Variabilität auf die Wasserkraftnutzung in der Schweiz, $\mathrm{PhD}$ Thesis, Faculty of Science, University of Bern,Berne, Switzerland, $206 \mathrm{pp}$.

Hawkins E, Sutton R (2012) Time of emergence of climate signals. Geophys Res Lett 39(1), L01702

Hegerl G, Zwiers FW, Braconnot P, Gillett N, Luo Y, Marengo Orsini J, Nicholls N, Penner J, Stott P (eds) (2007) Understanding and Attributing Climate Change. Climate Change 2007: The Physical Science Basis. Contribution of Working Group I to the Fourth Assessment Report of the Intergovernmental Panel on Climate Change. Cambridge University Press, Cambridge

Horton P, Schaefli B, Mezghani A, Hingray B, Musy A (2006) Assessment of climate-change impacts on alpine discharge regimes with climate model uncertainty. Hydrol Process 20(10):2091-2109

IPCC (2000) Emissions scenarios: A special report of IPCC Working Group III. Intergovernmental Panel on Climate Change, Geneva

Köplin N, Schädler B, Viviroli D, Weingartner R (2012) Relating climate change signals and physiographic catchment properties to clustered hydrological response types. Hydrol Earth Syst Sci 16(7):2267-2283

Köplin N, Schädler B, Viviroli D, Weingartner R (2013) The importance of glacier and forest change in hydrological climate-impact studies. Hydrol Earth Syst Sci 17(2):619-635

Ledbetter R, Prudhomme C, Arnell N (2012) A method for incorporating climate variability in climate change impact assessments: sensitivity of river flows in the Eden catchment to precipitation scenarios. Clim Chang 113(3-4):803-823

Linsbauer A, Paul F, Machguth H, Haeberli W (2013) Comparing three different methods to model scenarios of future glacier change in the Swiss Alps. Ann Glaciol 54(63):241-253

Liu Y, Zhang J, Wang G, Liu J, He R, Wang H, Liu C, Jin J (2013) Assessing the effect of climate natural variability in water resources evaluation impacted by climate change. Hydrol Process 27(7):1061-1071

Mann HB, Whitney DR (1947) On a test of whether one of two random variables is stochastically larger than the other. Ann Math Stat 18(1):50-60

Merz B, Maurer T, Kaiser K (2012) Wie gut können wir vergangene und zukünftige Veränderungen des Wasserhaushalts quantifizieren?: How well can we quantify past and future changes of the water cycle? Hydrol Wasserbewirtsch 56(5):244-256

Storch H, Zwiers FW (2001) Statistical analysis in climate research, 1st edn. Cambridge University Press, Cambridge

Storch H, Zwiers F (2013) Testing ensembles of climate change scenarios for "statistical significance". Clim Chang 117(1-2):1-9

van der Linden P, Mitchell J (2009) ENSEMBLES: Climate Change and its Impacts: Summary of research and results from the ENSEMBLES project, FitzRoy Road, Exeter EX1 3PB, UK. http://www.ensembles-eu.org/. Accessed 15 September 2013

Viviroli D, Zappa M, Gurtz J, Weingartner R (2009a) An introduction to the hydrological modelling system PREVAH and its pre- and post-processing-tools. Environ Model Softw 24(10):1209-1222

Viviroli D, Zappa M, Schwanbeck J, Gurtz J, Weingartner R (2009b) Continuous simulation for flood estimation in ungauged mesoscale catchments of Switzerland-part I: modelling framework and calibration results. J Hydrol 377(1-2):191-207

Viviroli D, Mittelbach H, Gurtz J, Weingartner R (2009c) Continuous simulation for flood estimation in ungauged mesoscale catchments of Switzerland-part II: parameter regionalisation and flood estimation results. J Hydrol 377(1-2):208-225

Wilcoxon F (1945) Individual comparisons by Ranking Methods. Biom Bull 1(6):80-83

Zappa M, Gurtz J (2003) Simulation of soil moisture and evapotranspiration in a soil profile during the 1999 MAP-Riviera Campaign. Hydrol Earth Syst Sci 7(6):903-919 